\title{
A negação do vazio por parte de Descartes: as críticas de Newton e Voltaire
}

\author{
Veronica F. B. Calazans \\ verocalazans@hotmail.com \\ Universidade de São Paulo, São Paulo, Brasil
}

resumo As críticas de Newton e Voltaire endereçadas à negação do vazio por parte de Descartes compartilham uma estrutura básica: ambos parecem concordar que tal tese cartesiana conduz a implicações indesejáveis tanto no campo da mecânica, quanto no que diz respeito à teologia. Entretanto, embora Newton admita as implicações teológicas da negação do vazio, elas não constituem o fim último de sua crítica, o que parece ocorrer na crítica de Voltaire. Ao contrário, os argumentos newtonianos para assumir o vazio encontram na mecânica não apenas um campo de prova; eles constituem uma parte importante da fundamentação de um dos pilares do newtonianismo: o espaço absoluto.

palavras-chave Voltaire; Newton; Vazio; Mecânica; Espaço; Descartes

Descartes admitia um Deus criador e causa de tudo. Mas negava a possibilidade do vazio. Epicuro negava o Deus criador e causa de tudo, e admitia o vazio. Ora, era Descartes que deveria negar um Deus criador, e Epicuro admiti-lo. (VOLTAIRE, 1996, p.32).

Logo em uma primeira leitura, fica clara a crítica de Voltaire à negação do vazio por parte de Descartes e o ponto central dessa crítica: negar o vazio significaria negar a possibilidade de um Deus criador e causa de tudo. Não sem razão, este é também um elemento central da crítica de Newton a Descartes. Inicialmente um atento leitor de Descartes, Newton rompe 
definitivamente com as concepções cartesianas e a assunção do vazio exerce um papel fundamental nessa virada. $\mathrm{O}$ que me proponho a investigar, aqui, é em que medida pode-se afirmar que a crítica de Voltaire está assentada sobre os mesmos fundamentos da crítica newtoniana e motivada pelas mesmas razões. Em outros termos, a consequência da impossibilidade de um Deus criador parece ser o fim último, e ao mesmo tempo único, da crítica deVoltaire à negação cartesiana do vazio. Por outro lado, embora Newton não negligencie as implicações teológicas das teses de Descartes, o absurdo da negação do vazio é evidenciado no interior da mecânica, através da concepção de movimento decorrente de tal negação. Seria, então, a mecânica apenas um âmbito para provar a existência do vazio com vistas às suas implicações teológicas? E nesse caso não haveria prejuízo em ocultar a parte do argumento relativa à mecânica, pois Voltaire estaria contemplando o objetivo final da crítica de Newton. Ou, ao contrário, estamos diante de duas críticas em que a negação do vazio ocupa estatutos diferentes embora convergentes de alguma maneira?

No capítulo 2 da primeira parte dos Elementos da Filosofia de Newton, Voltaire trata das propriedades do espaço e da duração afirmando, primeiramente, a tese de Newton de que espaço e duração são "seres cuja existência se segue do próprio Deus". Em linhas gerais, tal tese está sustentada do seguinte modo: Deus, por ser infinito, está em todo lugar, portanto, existe um espaço infinito; e, por ser eterno, dura por toda a eternidade e, portanto, essa eterna duração é real. Por ora, considerarei apenas a discussão a respeito do espaço.Voltaire destaca a disputa entre Leibniz e Clarke, sendo este último o porta-voz das teses newtonianas, a respeito do espaço puro. Nela, Clarke caracteriza o espaço através do consagrado termo sensorium que, devido à limitação de qualquer língua para falar de Deus, presta-se como uma satisfatória aproximação. Ou seja, se Deus vê e age em todo lugar, ele está em todo lugar, já que ninguém pode agir onde não está. Nesse sentido, o espaço seria como que um sensorium de Deus o que significa dizer que sua existência se segue de Deus.

Leibniz, por sua vez, sustenta que o espaço não possui uma existência real. Ele é apenas uma relação que percebemos entre os corpos e suas distâncias: em outras palavras, não há sentido em assumir a existência de espaço desvinculado da matéria, ou de um espaço puro, como dizVoltaire. Tomemos, aqui, uma citação que evidencia o ponto central da discussão: 
É bom prestar atenção a este antigo argumento, ao qual nunca se respondeu. Se um homem, nos limites do universo, levantar seu braço, este braço deverá ficar no espaço puro: pois não ficaria no nada; e se se responde que o braço ainda está na matéria, o mundo, neste caso, é infinito, logo, o mundo é Deus. (VOLTAIRE, 1996, p.31).

Voltaire traça uma importante distinção entre o espaço infinito (que existe necessariamente já que Deus é infinito e existe necessariamente) e a matéria que, ao contrário, não existe necessariamente, pois se ela fosse infinita, a exemplo do espaço, deveria ser uma propriedade essencial de Deus, ou o próprio Deus. Trata-se, então, de uma suposta consequência importante e teologicamente nefasta da tese de Leibniz ou de qualquer outro que não assuma a existência de um espaço puro, a saber, a de que a matéria, neste caso, assumiria o mesmo estatuto do espaço, de existir necessariamente, e sendo necessária, sua criação não seria decorrente da vontade livre do criador.

Cabe, então, esclarecer o que Newton entende por extensão, ou seja, como ele fundamenta a existência do espaço absoluto e como distingue a matéria finita do espaço puro e infinito; e, portanto, como ele define os corpos. Para tanto, faço uma remissão ao manuscrito de 1670, convencionalmente chamado de "De Gravitatione”. Antes, porém, é preciso investigar, qual a posição de Descartes frente a essa questão a fim de analisar as críticas de Voltaire e de Newton.

O sistema mundi cartesiano está, em última análise, assentado sobre um princípio metafisico: o dualismo, ou seja, a distinção substancial entre corpo e alma. Pode-se considerar que o dualismo tem como consequência direta um outro princípio cartesiano fundamental: a identificação cartesiana entre espaço e matéria. A questão a ser considerada aqui é a de saber qual a concepção de movimento que é gerada por essa identificação; visto que será - justamente a concepção de movimento - um dos principais alvos da crítica newtoniana à filosofia de Descartes, na medida em que, segundo Newton, ela evidencia o absurdo da negação do vazio. 
Segundo Descartes, ao examinarmos a ideia que temos de corpo, consideramos que se trata de "uma substância extensa em comprimento, largura e altura" (Pr. II, 11), coincidindo, então, com a ideia de espaço. Assim, é somente pelo pensamento que espaço e corpo se diferem, pois a extensão, que constitui o corpo, do mesmo modo constitui o espaço, ou seja, a natureza de ambos é a extensão. Corpo e espaço "só se diferem entre si como a natureza do gênero ou da espécie difere da natureza do indivíduo" (idem). Fica, portanto, estabelecida uma identidade entre a matéria e o espaço, visto que compartilham a extensão como atributo essencial. Assumindo tal identidade, assume-se também uma total incompatibilidade com qualquer tentativa de introduzir o vazio nesse sistema. Entretanto, embora espaço e corpo não sejam distintos na medida em que possuem uma natureza comum, Descartes afirma que é somente pelo pensamento que eles se diferem.

O pensamento atribui ao corpo uma extensão particular; isso porque se considera que esse corpo pode ser transportado, ou seja, é uma extensão que pode mudar de lugar. Da mesma forma, o pensamento atribui ao espaço uma extensão que, segundo Descartes, é vaga: determinamos o espaço a partir de certos corpos que consideramos externos e imóveis. Ao mover um determinado corpo, não pensamos que transportamos também a extensão que ele ocupava, ao contrário, acreditamos que ela ainda está lá, pois sua posição não se alterou com relação aos tais corpos externos. Se aceitarmos isso, devemos aceitar também que a extensão que antes era ocupada pelo corpo (extensão particular), pode agora ser ocupada por outro corpo ou, até mesmo, pelo vazio. Porém, ainda segundo Descartes, essa é uma noção vulgar de espaço e leva ao engano e ao relativismo.

Da identificação entre espaço e matéria segue-se uma impossibilidade de que um ocorra sem o outro. Então, se todo o espaço é matéria, não pode haver nele aquilo que se chama de vazio.Além disso, a matéria é una; pois, ao se considerar qualquer porção de matéria - ou qualquer outro possível mundo material - será necessário admitir que em sua essência ela é puramente extensão, como tudo aquilo que é material, e por isso, porque toda matéria compartilha da mesma essência, não seria possível conceber nenhuma outra matéria. "Logo, só há uma matéria em todo o universo e só a conhecemos porque é extensa" (Pr. II 23). Se for assim, a matéria, por essência, é homogênea; entretanto, ela se manifesta indiscutivelmente 
de forma heterogênea; o que somente é possível através do movimento, que gera divisibilidade: "todas as propriedades que nela (na matéria) apercebemos distintamente apenas se referem ao fato de poder ser dividida e movimentada segundo as suas partes e, por consequência, poder receber todas as afecções resultantes do movimento dessas partes” (Pr. II 23). Consequentemente, o movimento torna-se condição para a divisibilidade da matéria, na medida em que, para dividir duas partes quaisquer, é necessário separá-las. Ou seja, o movimento é o mais direto responsável pela diversidade de estados em que a matéria se encontra disposta, garantindo que esses estados possam ser apreendidos separadamente.

Cabe, então, perguntar pelo estatuto do movimento no sistema de mundo cartesiano, visto que, se por um lado o único atributo essencial à matéria é a extensão, por outro, o movimento não pode ser posto no mesmo nível das demais qualidades da matéria, na medida em que todas elas resultam do próprio movimento. Portanto, o movimento assumiria, para Descartes, um papel de mediação entre a extensão e as demais qualidades, sem ser, ele mesmo, uma delas. Dito de outro modo, se a natureza da matéria é, unicamente, a extensão, ela é essencialmente homogênea. Opondo-se a isto, ao menos aparentemente, o que os sentidos apreendem da matéria é a sua heterogeneidade, ou seja, os sentidos apreendem aquelas outras qualidades que não constituem a natureza dos corpos. Ora, se é o movimento que possibilita à matéria homogênea apresentar-se de maneiras diversificadas, podemos afirmar que ele tem um papel mediador entre o atributo que constitui a essência da matéria e a maneira como essa mesma matéria se apresenta aos sentidos, ou seja, aquelas qualidades disposicionais.

Essa mediação - entre a extensão e as demais qualidades - só é possível pelo status que o movimento ocupa no sistema cartesiano e a garantia dessa atribuição passa pela possibilidade de oferecer uma definição de movimento, uma tarefa que Descartes enfrenta na Segunda Parte dos Princípios. Ele identifica duas definições possíveis: aquela que define o movimento segundo o senso comum e a que define o movimento "verdadeiramente".

A principal consequência da distinção citada acima entre matéria e espaço é a concepção vulgar de movimento. Segundo o senso comum, o movimento é a "ação pela qual um corpo passa de um local para outro” (Pr. II 24). Já aí, Descartes pretende eliminar a multiplicidade de 
sentidos dada ao movimento pela tradição aristotélica, ao afirmar que não é "necessário supor outro (sentido para o movimento) na natureza" (idem). Porém, essa definição ainda deixa espaço para certo relativismo na medida em que, assim como se pode afirmar que uma coisa muda e não muda de lugar ao mesmo tempo, se pode afirmar também que um corpo ao mesmo tempo está em movimento - com relação a um certo local - e não está em movimento - com relação a outro; tal como no exemplo do homem sentado na popa de um barco:

"Por exemplo, se vemos um homem sentado na popa de um barco que o vento leva para fora do porto e só fixarmos o barco, parecer-nos-á que este homem não muda de lugar, porque vemos que se mantém sempre na mesma posição relativamente às partes do barco; mas se fixarmos as terras vizinhas, parecer-nos-á que este homem muda continuamente de lugar porque se afasta de umas e aproxima-se de outras." (Pr. II, 13).

É justamente para eliminar esse relativismo que Descartes se empenha em "saber o que é verdadeiramente o movimento", e conclui que "o movimento é a translação de uma parte da matéria ou de um corpo da proximidade daqueles que lhe são imediatamente contíguos" (Pr. II 25). Dessa maneira, ele substitui a noção de corpo pela de "tudo aquilo que é transportado conjuntamente" (idem), e estabelece como único referencial aquela porção de matéria que circunda o corpo. Isso permite dizer que "só podemos atribuir ao mesmo móbil um único movimento pois só existe uma determinada quantidade de corpos que o podem tocar ao mesmo tempo" (Pr. II 28). Porém, para que essa vizinhança contígua possa servir de referencial, é necessário fixá-la, atribuindo-lhe o estado de repouso. Isso significa dizer que a atribuição de movimento a um corpo ainda se faz mediante a sua relação com outros; de tal modo que, se porventura fixarmos o corpo ao qual antes atribuíamos movimento, teremos que atribuir movimento à sua vizinhança contígua, que anteriormente havíamos posto em repouso. Além disso, da substituição da noção de corpo pela de "tudo aquilo que é transportado conjuntamente", decorre o fato de que um mesmo corpo pode participar de diversos movimentos distintos, na medida em que compõe várias partes de matéria:

"Por exemplo, se um marinheiro ao passear no seu barco trouxer consigo um relógio, ainda que as rodas deste tenham um único 
movimento que lhes é próprio, é claro que fazem parte do movimento do marinheiro que passeia, uma vez que constituem um corpo que é conjuntamente transportado; também (...) participam do movimento do barco, (...) do [movimento] do mar, (...) e também do [movimento] da Terra." (Pr. II, 31).

Desse modo, Descartes admite que, embora haja apenas um movimento que se pode atribuir verdadeiramente a determinado corpo, os inúmeros movimentos dos quais ele participa - como parte de outros corpos -, igualmente, pertencem a ele: "todos estes movimentos estão nas rodas deste relógio" (idem). Entretanto, somente podemos ter um conhecimento certo daquele movimento que é próprio de cada corpo, e, portanto, bastará que este seja considerado.

\section{III}

Newton inicia o manuscrito De Gravitatione et Aequipondio Fluidorum, com quatro definições que, logo a uma primeira leitura, apontam para uma substancial diferença entre seu sistema mundi e o cartesiano. As definições são as seguintes: "Lugar é uma parte do espaço que uma coisa enche adequadamente", "Corpo é aquilo que enche um lugar", "Repouso é a permanência no mesmo lugar" e "Movimento é a mudança de lugar". Fica clara, aqui, uma distinção entre corpo e espaço que atinge uma das bases da doutrina cartesiana (no que se refere ao mundo físico): a identidade entre matéria e extensão. Da mesma maneira, a definição de movimento leva em conta as partes do espaço, ao invés da posição dos corpos vizinhos, como em Descartes. São estes os dois alvos principais da crítica newtoniana a Descartes, no texto acima citado. Porém, não é sem razão que Newton os põe em cheque, visto que, como vimos anteriormente, a concepção cartesiana de movimento depende diretamente do princípio da identidade entre matéria e extensão; e, por outro lado, é responsável direta pelo modo como se organiza todo o sistema. Resta saber qual o percurso dessa crítica, com o propósito de mostrar quais os fundamentos erguidos por Newton a partir dela e de que modo eles são estabelecidos. 
A crítica à noção cartesiana de movimento compreende duas partes bem distintas: em primeiro lugar, Newton mostra em que medida ela se contradiz internamente; e, a seguir, apresenta as consequências, tidas por ele como absurdas, que dela podem ser retiradas. A primeira dessas contradições internas refere-se a uma passagem que se encontra na Parte Terceira dos Princípios, Artigo 140. Lá, Descartes afirma que a Terra, assim como os outros planetas, tem uma tendência a afastar-se do Sol, e por isso mantém sua devida distância com relação a ele.Vale notar, que nesse caso o Sol é estabelecido como referencial para o movimento dos planetas. Ora, se o Sol é um corpo distante, isso caracteriza justamente a noção vulgar de movimento que já havia sido rejeitada. Igualmente, "Descartes parece contradizer-se ao postular que a cada corpo compete um movimento individual, conforme a natureza das coisas" (NEWTON, 1979, p. 212). A contradição reside no fato de, segundo Newton, a vizinhança contígua que Descartes toma por referência não estar em repouso, mas apenas parecer estar. Aliás, é o próprio sujeito quem a considera em repouso a fim de atribuir movimento a um determinado corpo. Então, como se poderia afirmar que esse movimento é o único conforme a natureza das coisas, visto que seu referencial foi deliberadamente estabelecido? E, por último, Descartes sustenta que, embora todo corpo participe de incontáveis movimentos, enquanto parte de outros corpos, cada um deles possui apenas um movimento "segundo a verdade das coisas". Assim, é contraditório dizer que certos movimentos não são conforme a verdade das coisas, na medida em que se admite que eles constituem movimentos realmente naturais, pois o corpo realmente faz parte do movimento de outros corpos. Por isso, porque são "realmente naturais", não se pode negar que esses movimentos sejam conformes à verdade das coisas e, portanto, sejam movimentos em sentido filosófico.

$\mathrm{Na}$ segunda parte dessa crítica, são elencadas oito consequências do ensinamento de Descartes no que concerne ao movimento. Em primeiro lugar, considerando um corpo qualquer, em movimento, podemos dizer que apenas sua superfície externa move-se no sentido estrito do movimento cartesiano; pois, se as suas partículas internas não se deslocam com relação à superfície externa (sua vizinhança contígua), elas não se movem com o movimento do corpo, propriamente dito, mas apenas participam desse movimento. A segunda consequência é a de que não há um 
movimento verdadeiro e absoluto. Segundo Newton, ao atribuirmos movimento a um corpo, em sentido próprio, não podemos negar essa atribuição às suas partes, se admitirmos que elas participam desse movimento. Ou seja, se um corpo participa do movimento de diversos outros, como afirma Descartes, todos esses movimentos estão em suas partículas, "no sentido verdadeiro e filosófico", e não se pode dizer que um entre eles seja absoluto. Em terceiro lugar, o movimento, no sentido cartesiano, pode ser gerado sem a ação de nenhuma força. Considerando, por exemplo, um corpo em rotação e cuja vizinhança contígua encontra-se no mesmo estado. Dizemos que ele está em repouso, pois não se desloca com relação a ela. Entretanto, se pararmos essa vizinhança sem aplicar nenhuma força ao corpo, do mesmo corpo diz-se que, agora, está em movimento. Disso decorre a quarta consequência, ainda mais espantosa: "o próprio Deus poderia não gerar movimento em alguns corpos, mesmo que os impulsionasse com a maior força" (NEWTON, 1979, p. 214).

Em quinto lugar, pautando-se pela concepção cartesiana, dois corpos em repouso podem mudar suas posições relativas. É o caso, por exemplo, dos planetas: eles estão em repouso, pois não se movem com relação à sua vizinhança, ou seja, ao fluido que os envolve. Porém, a posição de cada um deles varia constantemente com relação aos outros. Diretamente ligada a esta última, a sexta consequência é a de que dois corpos que mantém a mesma posição relativa podem estar um em repouso e o outro em movimento. E, em sétimo lugar, Newton afirma que nem sempre podemos dizer com segurança da vizinhança contígua de um certo corpo, se ela está em repouso ou em movimento.

Finalmente, uma dupla consequência por si só, evidencia o absurdo do ensinamento de Descartes; segundo Newton, porque tal ensinamento nos "leva a concluir que um corpo em movimento não tem nenhuma velocidade determinada (primeira consequência) e nenhuma linha definida (segunda)" (NEWTON, 1979, p. 216). O que se segue daí é ainda mais grave, por abalar diretamente as duas primeiras leis cartesianas do movimento: "não se pode afirmar que a velocidade de um corpo que se move sem resistência seja uniforme, nem se pode dizer que é reta a linha na qual se efetua o seu movimento" (idem). Apresentadas essas oito "consequências do ensinamento cartesiano", a questão que se impõe é a de saber em que se sustentam essas afirmações de Newton. 
Primeiramente, é preciso retomar a noção cartesiana de lugar. Este é determinado pela posição da vizinhança contígua ao corpo que se está considerando. Nesse caso, como é possível determinar o ponto de partida do movimento desse corpo? Newton responde: é simplesmente impossível. Ao iniciar-se o movimento, aquela vizinhança que circundava o corpo, anteriormente, é desfeita. E, mesmo que se pretenda determinar o lugar de início do movimento a partir de corpos distantes (seguindo a concepção vulgar), o problema se mantém; já que, no sistema cartesiano, pode-se dizer de todos os corpos que, mesmo que não estejam verdadeiramente em movimento, participam do movimento de outros corpos. Então, pode-se dizer que o lugar existe apenas enquanto os corpos mantêm as mesmas posições. Pois bem, em se tratando do movimento de um corpo, assim que ele deixa o seu lugar de origem, esse lugar deixa de existir e, portanto, não pode mais ser determinado.

Disso decorre que não é possível determinar o espaço percorrido por um corpo, visto que não se consegue encontrar seu ponto de origem. $\mathrm{Ou}$ seja, não há como saber qual o comprimento, qual a distância percorrida. Vale notar que a velocidade de um corpo é obtida pela distância percorrida em um certo intervalo de tempo. Por isso mesmo - porque a velocidade depende da distância percorrida -, Newton conclui que "o movimento cartesiano não é movimento, pois não tem velocidade" (NEWTON, 1979, p. 217).

Pelas mesmas razões, assim como não se pode determinar o lugar do movimento, também não se podem encontrar seus pontos intermediários. Assim, tendo em vista as duas primeiras leis do movimento, ambas estão comprometidas. A primeira, porque não se pode afirmar que a velocidade de um corpo, que se move sem resistência, é uniforme; uma vez que, como já vimos, o corpo nem mesmo tem velocidade. A segunda, pela impossibilidade de se obter a localização dos pontos intermediários do movimento, o que evidentemente impediria a qualquer um de afirmar que um corpo se desloca em linha reta.

Destacamos essa dupla consequência porque ela evidencia um problema que, segundo Newton, é crucial para provar o absurdo do sistema cartesiano: a definição de lugar. Até agora está provado que essa definição de lugar tem como produto uma concepção de movimento que gera, por sua vez, consequências absurdas. Entretanto, esta definição está firmada 
em certas bases que, por isso, serão alvejadas pela crítica, daqui por diante. Isso fica claro ao levar-se em conta que o problema da definição de lugar é que ela se estrutura a partir de corpos que, de um modo ou de outro, estão constantemente em movimento. É preciso que se encontre algo destituído de movimento a que se possa referir a definição de lugar e, assim, possibilite uma coerente atribuição de movimento aos corpos. Dito isto, qual seria o melhor candidato para assumir essa condição? O espaço, a extensão por si mesma, dirá Newton. E, para tanto, é imprescindível distinguir o espaço, destituído de movimento, dos corpos, como coisas móveis.

A tarefa de explicar o que é a extensão é iniciada por sua parte negativa, a saber, a de explicar o que ela (a extensão) não é. A extensão não é um nada absoluto: ela tem uma maneira própria de existir. Entretanto, ela não é uma substância, nem um acidente, pois sua maneira de existir difere da maneira de um e de outro. Da maneira da substância, porque a extensão "não é absoluta em si mesma, mas é antes como se fosse um efeito emanante de Deus" (NEWTON, 1979, p.218). Além disso, aceita-se que a substância deve ter a capacidade de agir sobre as coisas. Por exemplo, os corpos são móveis e podem excitar os sentidos. Não fossem essas capacidades - e outras do mesmo tipo -, dificilmente, segundo Newton, os corpos seriam caracterizados como substâncias.

A maneira de existir da extensão difere, igualmente, da do atributo, "já que podemos conceber claramente a extensão existindo sem qualquer sujeito" (idem). Newton afirma que podemos imaginar espaços fora do universo, ou seja, lugares onde não existem corpos e, nem por isso, a própria extensão deixa de existir. Se Deus destruísse um corpo, não se seguiria que o espaço que ele ocupava devesse também deixar de existir. Vê-se, então, que a extensão não é um acidente, na medida em que sua existência não depende de nenhum sujeito.

Por fim, não se pode definir a extensão como um nada. Segundo Newton, "ela é alguma coisa real, mais real do que um acidente, aproximando-se mais da natureza da substância" (idem). Isso se justifica pelo fato de que temos uma ideia clara da extensão, independentemente dos corpos; e, do nada não se pode ter ideia alguma. Além do mais, o nada não tem propriedades. Por esse motivo, Newton passa a enumerar as propriedades da extensão, pretendendo demonstrar que a extensão é alguma coisa e, ao mesmo tempo, "descrever o que ela é positivamente". 
Pode-se afirmar que o ponto de chegada da crítica ao movimento cartesiano é a afirmação de que "é necessário que a definição de lugares, e consequentemente também dos movimentos locais, seja referida a alguma coisa destituída de movimento, tal como a extensão sozinha, ou o espaço, na medida em que se vê que este se distingue dos corpos" (NEWTON, 1979, p. 217). A partir desse ponto, Newton vai expor as bases do seu próprio sistema. Dito de outro modo, já que está provada a necessidade de se considerar a "extensão sozinha", cabe mostrar em que consiste positivamente essa extensão, enumerando suas propriedades. Como ficará mais claro adiante, esse passo é, na realidade, o fundamento de um dos mais importantes princípios do sistema mundi newtoniano: o espaço absoluto.

Prosseguindo com as propriedades da extensão, o espaço newtoniano é, primeiramente, uma extensão que pode ser distinguida em partes. Isso não significa dizer que essas partes podem ser separadas, mas que se pode considerar superfícies que exercem a função de limite entre as partes do espaço. Isto é, ao tomarmos duas partes quaisquer do espaço, admitiremos necessariamente que o limite entre elas é uma superficie sem profundidade, caso contrário, as partes consideradas interpenetrar-se-iam em toda a profundidade dessa superfície-limite. Pelas mesmas razões, as superficies podem ser distinguidas em linhas que não possuem largura, e estas, por sua vez, em pontos que não possuem dimensões. Considerando que cada uma dessas partes é contígua a outras partes do espaço, Newton afirma que "em toda parte existem limites comuns a partes contíguas" (NEWTON, 1979, p. 219). Se for assim, em toda parte existem superficies, linhas e pontos-limite; e, portanto, "toda espécie de figuras". Ou seja, quando uma figura qualquer passa a ser percebida pelos sentidos como existente, isso não quer dizer que ela foi produzida. Apenas, sua representação corpórea tornou sensível o que "anteriormente era insensível no espaço". Essa propriedade da extensão será condição para uma posterior explicação da natureza dos corpos.

Está dito acima que cada parte do espaço é contígua a outras, isso se sustenta porque a extensão é infinita em todas as direções, ou seja, ao imaginarmos um limite no espaço, não poderemos conceber nada além dele que não seja outro espaço. Tem-se, até aqui, uma extensão infinita, mas que pode ser distinguida em partes. Entretanto, o que garante que essas partes não possam ser separadas, ou, em outras palavras, que essas 
partes sejam destituídas de movimento, como exige a própria crítica? Ao tentarmos atribuir movimento a uma parte do espaço, seremos obrigados a reconhecer que ela se move afastando-se das partes que lhe eram contíguas. Ora, não era justamente essa a base da concepção cartesiana, cuja absurdidade, segundo Newton, já foi suficientemente demonstrada? Fica, então, provada, pela própria crítica ao movimento cartesiano, a inconsistência de um espaço cujas partes são móveis. Além do mais, o único elemento que confere individuação às partes do espaço é a ordem em que elas se encontram. Assim, não faz sentido afirmar que uma parte do espaço mudou sua posição, pois, nesse caso, ela deixaria de ser aquela parte para ser outra. "Nem as partes da duração nem as do espaço apresentam qualquer indício de individualidade, se abstrairmos dessas, ordem e posição recíprocas, as quais, por conseguinte, não podem ser alteradas" (NEWTON, 1979, p. 222).

A propriedade seguinte é a de que o espaço constitui uma "disposição do ser enquanto ser". Nesse ponto, Newton retoma a crítica ao dualismo cartesiano, afirmando que nenhum ser pode existir sem que mantenha alguma relação com o espaço. Isso contraria radicalmente o dualismo; pois, na medida em que a extensão é atributo essencial do corpo, ela não pode pertencer às substâncias imateriais, nem mesmo como atributo não essencial. Se for assim, segundo Newton, tais substâncias nem ao menos existem: não estão em "nenhum lugar, nem em algum lugar". Ao contrário, todo tipo de substância tem relação com o espaço: "Deus está em toda parte, as inteligências criadas estão em algum lugar, o corpo está no espaço que ocupa". (NEWTON, 1979, p. 222).É estabelecida, então, uma concepção da extensão, imóvel e distinta da matéria, que se torna fundamento para a formulação do conceito de espaço absoluto. Tendo estabelecido, então, a distinção entre a extensão e os corpos materiais, Newton passa a considerar a questão de delimitar em que consiste a natureza de tais corpos.

A explicação da natureza dos corpos se faz, em um primeiro momento, em comparação com a natureza do espaço. Não sem propósito, a última propriedade do espaço - apresentada por Newton antes da explicação da natureza do corpo - é a de que "o espaço é eterno em sua duração e imutável em sua natureza” (NEWTON, 1979, p. 223). Como visto anteriormente, todas as substâncias devem ter alguma relação com o espaço 
para existir. Então, afirmar que o espaço não existiu em algum momento é comprometer a existência de Deus; pois, nesse tal momento, "Deus não teria estado em nenhum lugar". Daí se segue que não se pode negar a existência do espaço. Opondo-se a isto, "o corpo não existe necessariamente, mas apenas em virtude da vontade de Deus" (idem).

Aí se mostra uma dificuldade em se conhecer a natureza dos corpos, pois não podemos conhecer os limites do poder de Deus, ou seja, não sabemos como a matéria foi criada e se poderiam haver outros modos de criá-la. Diante dessa dificuldade, Newton afirma que não possui um conceito claro e distinto sobre isso. Por essa razão, ele não se compromete, inicialmente, em afirmar positivamente qual a natureza dos corpos: "prefiro descrever uma determinada espécie de ser, em tudo semelhante aos corpos, e cuja criação não podemos negar que esteja dentro do poder de Deus, de sorte que dificilmente podemos dizer que não seja corpo" (NEWTON, 1979, p. 223).

Em primeiro lugar, a descrição de tal ser semelhante aos corpos é deduzida da nossa faculdade de mover os próprios corpos. O argumento é o seguinte: se todo homem pode mover seu corpo exclusivamente pelo pensamento e a faculdade de pensamento é infinitamente maior, então o livre poder de mover os corpos não pode ser negado a Deus. Segue-se daí que, se Deus pode mover os corpos, pode também, exclusivamente pelo pensamento, evitar que um corpo penetre determinado espaço. $\mathrm{Ou}$ seja, Newton apresenta um argumento cuja conclusão confere a Deus o poder de mover os corpos e, "com base no mesmo argumento deve-se admitir que Deus, exclusivamente pelo pensamento e pela vontade, pode evitar que um corpo penetre qualquer espaço definido por certos limites" (NEWTON, 1979, p. 224).

Assim, supondo que Deus exercesse esse poder, ou seja, fizesse com que algum espaço fosse impenetrável aos corpos e, por conseguinte, refletisse a luz, o que nos impediria de considerar esse espaço limitado como um verdadeiro corpo? Nada, segundo Newton. Tal evidência seria fornecida pelos sentidos (únicos juízes nessa matéria): a impenetrabilidade faria com que esse espaço fosse tangível; a reflexão da luz o tornaria visível, opaco e colorido; e, ao ser atingido ele ressoaria como um verdadeiro corpo.

Contudo, esse espaço que, por hipótese, foi considerado como dotado por Deus de impenetrabilidade, até então, não está dotado de movimento, 
visto que se trata de uma parte do espaço imóvel. Então, para que esse determinado espaço possua todas as propriedades de um corpo, somos forçados a conceder que a impenetrabilidade possa ser transportada no espaço, segundo certas leis, sem que se alterem a quantidade e a forma desse espaço impenetrável. Ao aceitarmos essa premissa, somos levados a concluir que não há nenhuma propriedade dos corpos que esse espaço não possua: "teria forma, seria tangível e móvel, seria também capaz de refletir e ser refletido, constituindo também uma parte da estrutura das coisas" (NEWTON, 1979, p. 224). Desse modo, esse tal "ser semelhante aos corpos" seria "o produto da inteligência divina realizado em uma quantidade definida do espaço" e, portanto, seria capaz de operar sobre as nossas inteligências. Por um lado, Deus tem o poder de, apenas pela própria vontade, estimular a nossa percepção. Contudo, ele pode, igualmente, fazê-lo através dos efeitos da sua vontade.

Então, supondo que todo o universo seja composto por esses seres, ele não se comportaria de forma diferente daquela que percebemos, de tal modo que, "tais seres ou seriam corpos, ou semelhantes a corpos". Isso permite que Newton defina os corpos do seguinte modo: "determinadas quantidades de extensão que o Deus onipotente dota de certas condições" (NEWTON, 1979, p. 224).

Newton expõe, então, três condições a fim de definir o que são os corpos. Primeiramente, eles devem ser móveis. Já que são quantidades do espaço absoluto, os corpos distinguem-se deste pela mobilidade, ou seja, por poderem ser deslocados de um espaço ao outro. A segunda condição é a impenetrabilidade: dois corpos não podem coincidir na mesma parte do espaço. Quando eles se encontram, devem parar e serem refletidos conforme as leis do movimento. Por fim, estes seres, para que sejam corpos, devem atingir a nossa inteligência, excitando as percepções dos sentidos e da imaginação. Entretanto, em certo sentido, Newton não se compromete com uma definição positiva da natureza dos corpos, visto que as condições acima citadas são inferidas a partir de uma hipótese, qual seja, a de que aqueles seres, dotados por Deus de impenetrabilidade e mobilidade, sejam os mesmos corpos que afetam as nossas inteligências.

Por fim, tendo exposto a crítica à concepção cartesiana de movimento e a consequente distinção entre espaço e matéria, é preciso mostrar qual a concepção de movimento que se apoia nos novos fundamentos erguidos 
a partir da crítica. Para tanto, considero o texto dos Princípios Matemáticos de Filosofia Natural, mais precisamente o Escólio das Definições.

Vimos que o ponto central da crítica diz respeito à definição do lugar a partir do qual se estabelece o movimento de um corpo. Por essa razão, inicio tratando da distinção newtoniana entre lugar relativo e absoluto. Newton define o lugar como "uma parte do espaço que um corpo ocupa” (NEWTON, 1990, p. 6). Se o lugar é definido com relação ao espaço absoluto, então dizemos que é lugar absoluto; analogamente, se é definido com relação ao espaço relativo, é lugar relativo. Vale retomar, aqui, que o espaço absoluto é aquele que "em sua natureza, sem relação com qualquer coisa externa, permanece similar e imóvel” (NEWTON, 1990, p. 7). Já o espaço relativo é uma medida móvel do espaço absoluto, determinada, através dos sentidos, por sua posição com relação aos corpos. O espaço relativo é, muitas vezes, tomado como imóvel. Por exemplo, medimos os espaços subterrâneos, aéreos e terrestres por meio de suas posições com relação à Terra.

Segundo Newton, os únicos movimentos absolutos são as translações a partir dos lugares absolutos. Entretanto, as partes do espaço não podem ser distinguidas pelos sentidos e, por isso torna-se impossível distinguir, pelos sentidos, o movimento relativo do movimento absoluto; além do mais, "pode ser que não haja um corpo realmente em repouso, com relação ao qual os lugares e movimentos de outros possam ser referidos" (NEWTON, 1990, p. 9). Nesse caso, o que permitiria a distinção entre as duas espécies de movimento? Ou seja, a questão é a de saber o que permitiria a Newton escapar da sua própria crítica, na medida em que uma das consequências absurdas da concepção cartesiana de movimento era justamente a impossibilidade de distinguir o movimento absoluto entre os vários movimentos de um corpo. A resposta que Newton oferece a essa questão é a de que é possível diferenciar movimento absoluto de movimento relativo - e, analogamente, repouso absoluto de repouso relativo - por meio das suas propriedades, causas e efeitos.

Nesse ponto, cabe retomar as consequências da concepção cartesiana de movimento. Ao determinar conceitualmente as propriedades, causas e efeitos do repouso e do movimento absolutos, Newton parece que pretende oferecer as razões pelas quais sua concepção de movimento escapa à crítica, que ele próprio dirige, à concepção cartesiana, no que se refere 
às suas consequências. Primeiramente, Newton afirma que o repouso tem como propriedade "que os corpos realmente em repouso repousem uns com relação aos outros" (NEWTON, 1990, p. 9). Recordemos as consequências quinta e sexta, expostas acima. Newton afirmara, referindo-se ao "ensinamento cartesiano", que:

"parece contrário à razão admitir que os corpos mudam suas distâncias e posições relativas sem movimento físico (...) por outra parte, parece igualmente contrário à razão admitir que, de vários corpos que mantêm as mesmas posições relativas, alguns se movem fisicamente, ao passo que outros permanecem em repouso." (NEWTON, 1979, p. 215).

Ora, ao introduzir as noções de lugar, movimento e repouso absolutos, Newton assegura que os corpos em repouso mantenham suas posições relativas. Embora não tenhamos acesso ao lugar absoluto por meio dos sentidos, podemos supor um corpo, nas regiões remotas para além das nossas, que esteja verdadeiramente em repouso. Se for esse o caso, os corpos das nossas regiões que estiverem em repouso absoluto devem manter suas posições com relação a esse corpo e, consequentemente, suas posições recíprocas.

A segunda propriedade é a de que as partes que conservam suas posições com relação ao seu todo participam do movimento desse todo. Novamente, recordemo-nos da primeira consequência do ensinamento de Descartes, qual seja, a de que somente a superfície externa move-se com o movimento do corpo, ao passo que a superfície interna move-se por participação. Isso ocorre, como vimos, em virtude de a definição cartesiana de lugar se dar a partir da vizinhança contígua. Tendo Newton mostrado o absurdo desse procedimento, e estabelecido como referência um lugar (ou corpo) externo àquele ao qual se atribui o movimento, suas partes compartilham verdadeiramente desse movimento, enquanto mantiverem suas posições com relação a ele.

A terceira propriedade é a de que "se um lugar é movido, seja o que for colocado ali dentro move-se junto com ele; e, portanto, um corpo que é movido a partir de um lugar em movimento, compartilha também do movimento do seu lugar" (NEWTON, 1990, p. 10). Então, os movimentos que se dão a partir de lugares em movimento são apenas partes do movimento inteiro, absoluto. Este, por sua vez, é composto pelo movimento 
do corpo com relação ao seu lugar, somado ao movimento desse lugar com relação ao lugar a partir do qual se move, e assim por diante até que se tenha como referência o espaço imóvel.

Como dito acima, o movimento absoluto se distingue do relativo por suas propriedades, causas e efeitos. Passo, então, à consideração das causas pelas quais se garante essa distinção: "as forças imprimidas sobre os corpos para gerar movimento”. As consequências terceira e quarta, da crítica, nos mostraram que, segundo a concepção cartesiana, o movimento pode ser gerado sem a ação de uma força e, por isso, o próprio Deus não poderia gerar movimento em alguns corpos. Contra isso, Newton afirma que "o movimento verdadeiro não é nem gerado nem alterado, a não ser por alguma força imprimida sobre o corpo movido" (NEWTON, 1990, p.11), e nisso ele distingue-se do movimento relativo que, este sim, pode ser gerado ou alterado sem a ação de força alguma.Voltando ao caso em que um corpo move-se a partir de um lugar em movimento, se uma força é aplicada a esse corpo, mas também é aplicada ao lugar, sua condição não se altera. Por outro lado, como o movimento absoluto ocorre a partir do espaço imóvel, toda e qualquer força aplicada a um corpo, tomado deste modo, altera o seu estado: "E, portanto, qualquer movimento relativo pode ser modificado quando o movimento verdadeiro permanece inalterado, e o relativo pode ser preservado quando o verdadeiro sofre qualquer modificação. Assim, movimento verdadeiro de modo algum consiste em tais relações" (NEWTON, 1990, p.11).

Finalmente, considero os efeitos que distinguem o movimento absoluto do relativo. Esses efeitos são, segundo Newton, "as forças que agem no sentido de promover um afastamento a partir do eixo do movimento circular" (NEWTON, 1990, p. 11). A fim de ilustrar essa afirmação, Newton utiliza-se da consagrada "experiência do balde". Trata-se de um balde suspenso por uma corda e girado de modo que esta fique torcida. $\mathrm{O}$ balde é cheio, então, com água e ambos são deixados em repouso. Em seguida, uma força é aplicada girando o balde para o lado contrário à torção da corda, fazendo com que ela desenrole-se. No início do movimento, a superficie da água será plana; mas, conforme o balde for, gradualmente, comunicando-lhe movimento, a água começará a girar, afastando-se do meio e subindo pelos lados do balde. Assim, sua superfície tornar-se-á côncava. Em certo ponto da experiência, a água passa a realizar suas 
rotações nos mesmos tempos que o balde e, portanto, fica em repouso com relação a ele. Esse repouso é, obviamente, relativo. Entretanto, nesse ponto, pode-se medir o movimento absoluto da água por intermédio dessa tendência a afastar-se do eixo do seu movimento, tendência essa que chega ao seu ápice quando a água atinge o repouso com relação ao balde. Notemos, porém, que com isso Newton não pretende provar, por vias experimentais, a existência do movimento ou do espaço absolutos; antes, pretende mostrar de que modo os movimentos absolutos podem ser evidenciados por seus efeitos.

Assim, somente por meio das propriedades, causas e efeitos do movimento absoluto é que ele pode ser diferenciado do movimento relativo, evidenciando, consequentemente, a diferenciação, que não pode ser feita através dos sentidos, entre o espaço absoluto, imóvel e o espaço relativo.

\section{IV}

A crítica de Newton à concepção cartesiana de movimento atinge não apenas esse conceito, mas também todo o sistema e seus fundamentos. Isso porque o movimento assume, no sistema cartesiano, um estatuto privilegiado de mediador entre a matéria homogênea (essencialmente idêntica à extensão) e toda a diversidade em que ela se manifesta. Por isso mesmo, os princípios mecânicos do movimento são, em última análise, as Leis da Natureza, ou seja, as leis que regem o próprio sistema. Além disso, a definição de movimento, que se estabelece a partir da vizinhança contígua do corpo considerado, é fruto direto do princípio segundo o qual a matéria é idêntica ao próprio espaço.

Entretanto, as dificuldades insuperáveis, de ordem mecânica, a que conduziu tal concepção de movimento evidenciaram, através da crítica de Newton, a necessidade de pôr em questão, igualmente, os seus fundamentos: primeiramente, a identidade essencial entre matéria e extensão e, consequentemente, a negação do vazio.

Desse modo, se existiram razões teológicas para que Newton negasse, por meio da crítica, o dualismo metafísico, no que concerne à extensão, elas não foram as únicas. A consequente identidade essencial entre matéria e extensão produz uma definição de lugar - a partir do qual se atribui 
movimento a um corpo - que, levada a cabo, resulta em uma indeterminação do ponto de partida, da trajetória e da velocidade do corpo, que se considera em movimento, reivindicando, contraditoriamente, a impossibilidade do movimento.

A fim de desvencilhar-se da absurdidade dessa (entre outras) contradição, Newton estabelece a distinção entre a matéria (móvel) e o espaço indistinto e imóvel no qual ela move-se livremente: o espaço absoluto. Segue-se daí uma outra concepção de movimento (o movimento absoluto) na qual ele se refere não mais à vizinhança contígua do corpo, mas ao próprio espaço imóvel. As dificuldades metafísicas dessa distinção não podem ser desprezadas, a começar pela necessidade de se admitir o vazio; entretanto, do ponto de vista mecânico, ela estabelece novos rumos para a pretensão moderna de explicar o mundo segundo um sistema matematicamente estruturado.

Diante de tal cenário, pode-se dizer que a crítica que Newton dirige a Descartes no que diz respeito à identidade entre matéria e extensão, ou seja, à negação do vazio tem na mecânica não apenas um âmbito de prova, mas um fim em si mesmo. O papel dessa crítica é de fundamental importância para estabelecer os fundamentos da mecânica newtoniana. O abandono da concepção cartesiana de movimento e consequentemente de espaço exige, por parte de Newton, o comprometimento com um espaço absoluto, destituído de movimento, a partir do qual se pode estabelecer um referencial seguro para o movimento. O sistema mundi que resulta dá comporta o vazio já que a matéria não tem o caráter de necessidade do espaço. No entanto, tal exigência pode ser tomada como estritamente de ordem mecânica, mesmo assumindo suas implicações teológicas. O que se está pondo em cheque não é a possibilidade de que Newton tivesse razões teológicas para assumir o vazio. O ponto é que há um percurso independente no escopo da mecânica em que assumir o vazio é requisito para lançar os fundamentos de toda a explicação de mundo que será construída a partir daí. Por outro lado, a crítica que Voltaire endereça à negação cartesiana do vazio parece resolver-se no escopo da teologia; mas, principalmente, parece ter nas implicações teológicas seu fim último. O papel que a mecânica ocupa na crítica de Voltaire está restrito à função de provar a opinião de Newton a respeito do vazio: 
Não entramos aqui nos detalhes das provas físicas reservadas para outros capítulos. Basta assinalar que em tudo o que diz respeito ao espaço, (...), Newton seguia as antigas opiniões de Demócrito, Epicuro e de uma multidão de filósofos corrigidos por nosso célebre Gassendi.

(VOLTAIRE, 1996, p.33, grifo nosso)

Do que foi dito, se segue que podemos assumir as críticas de Voltaire e Newton ao pleno de Descartes como dois percursos distintos em suas finalidades, embora muito semelhantes em suas teses principais. Nesse sentido, o percurso de Voltaire evidencia o comprometimento com propósitos legitimamente newtonianos. Entretanto, estes mesmos propósitos ocupam estatutos diferentes para os dois autores. Para Newton, as implicações teológicas da assunção do vazio são consequências desejáveis, mas que não determinam, sozinhas, o percurso da crítica. Para Voltaire, as implicações mecânicas são relevantes apenas na medida em que fornecem um recurso de prova das opiniões de Newton. Ou seja, a mecânica assume estatutos diferentes para um e outro, tendo em vista que os fins últimos de suas respectivas críticas são distintos.

\section{Referências bibliográficas}

DESCARTES, R. Princípios da Filosofia. Tradução de João Gama. Lisboa: Edições 70 .

DESCARTES, R. 1982. Principia Philosophiae. Paris: J.Vrin. (Oeuvres de Descartes).

GARBER, D. 1992.Descartes' Metaphysical Physics. Chicago and London: The University of Chicago Press.

NEWTON, I. 1999. The Principia: Mathematical Principles of Natural Philosophy. Tradução de I. B. Cohen e A. Whitman. Berkeley: University of California Press.

NEWTON, I. 1979. Princípios matemáticos; Óptica; O peso e o equilíbrio dos fluídos. Traduções de Carlos Lopes de Matos, Pablo Rubén Mariconda e Luiz João Baraúna. São Paulo: Abril Cultural (Col. Os Pensadores). 
PANZA, M. 2003. Newton. Paris: Belles Lettres.

SLOWIK, E. 2002. Cartesian Spacetime: Descartes' Physics and the Relational Theory of Space and Motion.Dordrecht, Boston and London: Kluwer Academic Publishers.

VOLTAIRE. 1996. Elementos da Filosofia de Newton. Tradução de Maria das Graças S. do Nascimento. Campinas, SP: Editora da UNICAMP. WESTFALL, R. S. 1980. Never at Rest; a Biography of Isaac Newton. Cambridge: Cambridge University Press. 